\title{
Vergonha e fúria: cidadãos britânicos em protesto contra a intervenção militar de seu governo na Grécia (1944)
}

\author{
Shame and fury: british citizens protesting against their \\ government's military intervention in Greece (1944)
}

Felipe Alexandre Silva de Souza

Resumo: Nos últimos dias de 1944, o Governo de Unidade Nacional da Grécia — então recém desocupada pelos nazistas - entrou em choque armado contra guerrilheiros de esquerda organizados no Exército de Libertação do Povo Grego (ELAS), que havia passado os últimos três anos lutando contra a ocupação alemã. Os soldados britânicos que estavam em solo grego acabaram entrando no conflito contra a guerrilha, em consonância com a linha, defendida pelo primeiro ministro Churchill, de priorizar a defesa do governo helênico, um tradicional aliado de Londres. A política para a Grécia gerou consistente oposição, não apenas no Parlamento, mas também entre pessoas comuns, distantes dos círculos de poder público. Pretendemos fazer um resgate das expressões dessa oposição entre essas pessoas comuns, e examinar quais eram as bases que impulsionavam tal oposição. Por intermédio da análise das notícias e cartas veiculadas no diário The Daily Worker entre 5 e 25 de dezembro de 1944, constatamos que, na percepção desses opositores, a intervenção na Grécia colocou a Grã-Bretanha em colisão com os valores de democracia e liberdade que impulsionaram sua guerra contra o nazifascismo.

Palavras chave: Grã-Bretanha. Grécia. Guerrilha.

\begin{abstract}
In the last days of 1944, after the end of Nazi occupation, Greece's National Unity Government came into armed conflict with the left wing Greek People's Liberation Army (ELAS), a guerrilla group which had spent the last three years fighting the Nazi invaders. The British soldiers who were then stationed in Greek soil ended up joining the National Unity Government against ELAS, in accord with Prime Minister Churchill's agenda of defending the Greek government, London's traditional ally. That policy received a great amount of criticism, not only in Parliament, but also among ordinary people distant of political power. We aim to study how ordinary people expressed their views in order to understand on which grounds such opposition was elaborated. By analyzing readers' letters and news published in The Daily Worker newspaper between December 5th and December 25, 1944, we have deduced that, according to its opposers, British intervention in Greece was against the very ideals of democracy and freedom for which Britain fought the Axis powers.
\end{abstract}

Keywords: Great Britain. Greece. Guerrillas.

\footnotetext{
1 Doutorando em História pela Universidade Federal Fluminense. Bolsista do Conselho Nacional de Desenvolvimento Científico e Tecnológico (CNPq). ORCID: https://orcid.org/0000-0001-6576-9011. E-mail: felipedesouza1988@gmail.com
} 


\section{Introdução}

O declínio da supremacia global britânica foi um processo gradual e multifacetado. Arrighi (2010), por exemplo, localiza seus momentos iniciais na década de 1870, a partir de uma perspectiva econômica, contrapondo a desaceleração britânica à projeção crescente da Alemanha e dos Estados Unidos da América. Na segunda metade do século XX ainda era possível acompanhar o processo a partir da retração do Império Britânico: Londres viria a perder o controle político sobre a Malásia em 1957, sobre o Quênia em 1963 e sobre a Rodésia em 1965. Essa tendência de longa duração ficou mais explícita nos primeiros anos posteriores à Segunda Guerra Mundial, devido à exaustão financeira britânica e à emblemática independência da Índia e do Paquistão (1947). Com o respaldo das reflexões de Barraclough (1966), podemos dizer que o imediato pós-guerra foi um ponto de viragem fundamental nas relações de força mundiais, assinalando o fim da multissecular preponderância econômica, política e militar europeia - e em especial, desde pelo menos 1815, britânica - e a consolidação da hegemonia estadunidense.

Trata-se de um tema de grande escopo, que evidencia, em uma primeira aproximação, as decisões econômicas (e.g. a dependência crescente de auxílio financeiro estadunidense), as disputas políticas de cúpula (e.g. o governo de Clement Attlee aceitando a independência da Índia em 17 de agosto de 1947) e os grandes movimentos sociais pela emancipação em relação ao Império (e.g. a desobediência civil liderada por Mohandas K. Gandhi). Todavia, é sabido que as transformações históricas não se esgotam em episódios espetaculares e bem delimitados. Tendo isso em vista, pretendemos fazer um exercício de análise de um aspecto menos estudado do declínio da Grã-Bretanha: abordar qual teria sido a percepção de cidadãos britânicos comuns que se declaravam contrários à política exterior britânica nos últimos momentos da Segunda Guerra Mundial. A intenção foi captar quais eram os motivos expressos que impulsionaram essa oposição e salientar algumas das percepções sobre a política externa britânica em um período de decadência da projeção global britânica.

Concentramos a análise em torno de um acontecimento específico: a intervenção das tropas britânicas na Grécia em dezembro de 1944, quando o Governo de Unidade Nacional, formado após o fim da ocupação nazista do país dois meses antes, entrou em choque armado com os guerrilheiros do Exército de Libertação do Povo Grego, Ellinikós Laïkós Apeleftherotikós Stratós,(ELAS), braço armado da Frente de Libertação Nacional, Ethniko Apeleftherotiko Metopo (EAM), que combateu os alemães durante a ocupação. Os soldados britânicos, estacionados na Grécia desde a libertação do país (outubro de 1944), combateram o ELAS em defesa da monarquia grega, então aliada ao governo conservador de Winston Churchill. O embate gerou controvérsias na sociedade britânica, suscitando um debate público que ultrapassou as câmaras do Parlamento. Esse episódio é relevante por ser o ponto a partir do qual o público britânico passou a desenvolver maior interesse pela guerra civil grega (1943-1949) ${ }^{2}$, que por

\footnotetext{
2 Adotamos aqui a datação proposta por Gerolymatos (2016), que toma como início da guerra civil os choques entre os grupos de resistência que lutavam contra os nazistas enquanto a ocupação ainda estava em curso. Houve uma suspensão dos conflitos entre outubro e dezembro de 1944 e um novo intervalo entre fevereiro de 1945 e março de 1946. O fim definitivo da guerra se deu em outubro de 1949 , com a derrota da organização sucessora do ELAS, o Exército Democrático da Grécia (Dimokratikós Stratós Elládas - DSE), para as forças armadas da monarquia.
} 
sua vez foi uma contenda emblemática para o processo de descenso britânico: no curso dessa guerra, em 1947, o governo trabalhista de Clement Attlee renunciou à tradicional influência de Londres sobre Atenas e solicitou que Washington assumisse suas responsabilidades.

Por intermédio principalmente da análise de reportagens e cartas de leitores publicadas no jornal The Daily Worker, tentamos captar algumas evidências de como britânicos comuns contestavam a atuação de seu governo na Grécia. Nossa prioridade temporal será o período entre o dia 3 de dezembro de 1944 (o início do conflito em Atenas) e o dia 25 de dezembro do mesmo ano (quando Churchill participou de uma conferência em Atenas com o objetivo de colocar um fim à contenda).

O estímulo para este artigo advém das reflexões do historiador alemão Alf Lüdtke (1995) sobre os temas tratados nos estudos da história do cotidiano. Não pretendemos fazer história do cotidiano ${ }^{3}$, mas sim tomar como guia de reflexão uma questão que orbita as discussões sobre a cotidianidade: as pessoas comuns e suas diversas formas de lidar com mudanças históricas. Para Lüdtke, os debates historiográficos das décadas de 1970 e 1980 foram marcados por abordagens macroscópicas e pelos grandes temas tradicionais: a formação dos estados nacionais; as expansões coloniais; a generalização das relações sociais capitalistas; etc. Tais recortes teriam a tendência a escamotear a agência dos seres humanos concretos. A alternativa a essas perspectivas seria, para Lüdtke (1995), trazer a ação humana concreta para o centro da reflexão histórica - não a ação dos grandes líderes da chamada "história política tradicional”, mas as pessoas comuns, anônimas, em seus afazeres diários. Essa é preocupação da alltagsgeschichte (história do cotidiano), desenvolvida na Alemanha durante a década de 1980. É ressaltada, nessa perspectiva, a necessidade de estudar como as pessoas comuns se apropriam de seu mundo, e examinar como as imposições e os estímulos sociais são percebidos e processados.

Acreditamos que a reflexão acerca da projeção global britânica - um grande tema por excelência - possa ser enriquecida com as reflexões de Lüdtke. Colocamo-nos a questão: de que forma os britânicos comuns contrários às políticas externas de Londres fundamentavam tal oposição?

Tal questionamento nos leva à necessidade de se definir o que são as pessoas comuns. Bergerson, em seu trabalho Ordinary germans in extraordinary times (2004), traz uma acepção útil para nosso tema: pessoas comuns são aquelas fora dos círculos de poder público e que, consequentemente, não possuem a capacidade direta de tomar grandes decisões políticas. Acrescentamos à definição que as pessoas comuns tais como as trataremos aqui também não

\footnotetext{
3 Cotidiano é um termo de múltiplos significados, mas que poderíamos defini-lo sucintamente como a dimensão da vida social caracterizada pelo ordinário, pela repetição, pela rotina, onde as pessoas comuns levam e normalizam suas vidas (CORDEIRO; MAGALHÃES, 2017). Todavia, afirma Lüdtke (1995), a vida cotidiana não se esgota em seu caráter repetitivo que torna propício, nos indivíduos, o desenvolvimento de pensamentos e ações pragmáticos, eliminando incertezas constantes e permitindo maior facilidade na condução da vida, e que nos grupos sociais tende a levar à estabilidade da ordem social e à submissão da autoridade. Focar apenas nos elementos de repetição nos levaria a uma visão estrutural, na qual a vida cotidiana seria uma esfera estática totalmente subordinada a uma esfera não cotidiana na qual os fatos acontecem. Mais proveitosa seria uma abordagem da dimensão dinâmica do cotidiano, considerando-o lugar de transformações históricas, onde os indivíduos são simultaneamente objetos e sujeitos da história.
} 
fazem parte das hierarquias superiores de qualquer tipo de poder, seja ele governamental, econômico, cultural ou relativo a partidos políticos de oposição ao governo. ${ }^{4}$

Com base nessa perspectiva, pretendemos dar uma contribuição para a historiografia da guerra civil grega e da intervenção britânica nesse conflito. Desde o início do século XXI, os trabalhos acadêmicos acerca desse tema têm sido agraciados por uma variedade de novas abordagens. Segundo Sakkas, tanto a vertente tradicionalista ${ }^{5}$ da historiografia da guerra civil grega quanto os estudos revisionistas - as duas linhas de pesquisa dominantes entre as décadas de 1950 e 1980 - formulavam suas problemáticas de pesquisa em torno da questão da responsabilidade. Para os tradicionalistas, os líderes da EAM - compostos por membros do Partido Comunista Gregos, Kommounistikó Kommas Elládas (KKE) —, estavam menos preocupados em combater as forças do Eixo e mais focados em derrotar grupos guerrilheiros rivais, com o intuito de estabelecer em Atenas, por intermédio da força, uma ditadura nos moldes soviéticos. A intervenção militar britânica teria garantido, portanto, que a Grécia permanecesse um país livre e independente. Já as interpretações revisionistas ${ }^{6}$, embora não se furtem a análises críticas da guerrilha, em geral argumentam que o KKE e o ELAS eram organizações verdadeiramente democráticas que lutavam por uma Grécia independente, sem qualquer plano obscuro de favorecer Moscou. Os anseios por uma nação helênica livre teriam sido destruídos pela insistência britânica em manter a Grécia em situação de dependência.

Segundo Sakkas (2013), foi principalmente o contexto de fim da Guerra Fria que facilitou, a partir da década de 1990, a divulgação de novas perspectivas de pesquisa - que, embora muito variadas, normalmente são colocadas sob o termo de pós-revisionismo, por problematizarem tanto a perspectiva tradicionalista quanto a revisionista, chamando atenção para o que seria uma impossibilidade, diante das evidências disponíveis em taxar um ou outro grupo como principal responsável pelo conflito. No entanto, essa problematização passa a ter importância lateral: a ênfase em questões imediatamente políticas é reduzida e os aspectos econômicos e sociais recebem maior atenção. Entre os vários temas abordados pelos pós-revisionistas ${ }^{7}$, a intervenção britânica na Grécia também passou a ser vista sob novas perspectivas principalmente a partir de John Sakkas (2007), que examina o impacto que a política externa de Londres para a Grécia teve em diversas instâncias da população britânica - imprensa, organizações sindicais, partidos de oposição etc. A principal qualidade da pesquisa de Sakkas, em relação às

\footnotetext{
4 No trabalho citado, Bergerson faz uma história do cotidiano da cidade alemã de Hildesheim durante a era nazista, Para ele, a caracterização de comum (ordinary) não se esgotava na identificação de "[...] um conjunto particular de pessoas que permaneciam fora dos círculos de poder público e responsabilidade histórica” (BERGERSON, 2004, p. 6). Mais do que isso, ser comum, no contexto estudado pelo autor, era se engajar em artimanhas culturais específicas para a sobrevivência. As circunstâncias que abordaremos aqui são diferentes das que foram estudadas por Bergerson: as condições em que viviam os cidadãos britânicos na Grã-Bretanha dos últimos momentos da Segunda Guerra Mundial em muito divergiam daquelas com que os cidadãos alemães lidavam durante o III Reich. Portanto, não faz sentido, nos marcos deste trabalho, focar no que Bergerson chama de artimanhas de sobrevivência, e por isso trabalharemos apenas com o início de sua definição.

5 Além de C. M. Woodhouse (2004), considerado pioneiro entre os tradicionalistas, também se destacam, dentro dessa vertente, George Kousoulas (1965) e Edgar O' Balance (1966).

6 Dentre os revisionistas, podemos citar Constantinos Tsoukalas (1969) e John Iatrides (1972).

7 E.g. as mulheres e as relações de gênero durante a guerra civil grega, os refugiados e seus filhos, as questões étnicas, a construção da memória coletiva.
} 
tendências tradicionalistas e revisionistas, é a ênfase no fato de que a Grã-Bretanha não é um bloco monolítico que opera simplesmente como um vetor imperialista ou como mantenedor da liberdade, a depender da interpretação. Ao contrário, Sakkas indica que a intervenção na Grécia foi um processo complexo e contraditório, empreendido por milhares de pessoas exercendo as mais diversas tarefas, e parte integrante de intricadas lutas políticas que se desenrolavam em várias dimensões sociais, nas quais colidiam diferentes percepções do que deveria ser a política externa de Londres. Este artigo pretende se vincular à perspectiva apresentada por Sakkas e discutir, a partir da análise de reportagens e de cartas de leitores publicadas no Daily Worker, as expressões de descontentamento, dentro da sociedade britânica, quanto à intervenção de Londres na Grécia, e discutir os motivos expressos desse descontentamento.

\section{A hegemonia britânica sobre a Grécia}

O inverno de 1944 foi difícil para os gregos. Em outubro havia se findado a ocupação nazista sobre o país, iniciada em abril de 1941. As consequências foram devastadoras: a infraestrutura da nação estava em ruínas, o desemprego e a inflação atingiram níveis astronômicos, e era aguda a carência de alimentos e de combustível para aquecimento caseiro. Em meio a essa situação, cresciam as recriminações e acusações mútuas de traição e colaboracionismo (GEROLYMATOS, 2016). A EAM foi a principal organização de resistência de massa durante a ocupação, composta por uma coalizão de vários grupos liderados pelo Partido Comunista Grego (KKE). Por intermédio de seu braço armado, o ELAS, a EAM arcou com grande parte do esforço para expulsar os nazistas da Grécia, e no fim de 1944, contava com aproximadamente 750 mil membros e dispunha de massivo apoio popular (GEROLYMATOS, 2016).

Quando as forças do Eixo ocuparam a Grécia em abril de 1941, operadores militares britânicos deslocaram o rei George II e um pequeno gabinete de assessores para o Cairo, Egito. A política do Foreign Office, respaldada pelo primeiro ministro Winston Churchill, era fortalecer o governo grego no exílio como parte do esforço de guerra - acreditava-se que a monarquia poderia ser um elemento unificador do povo grego, um símbolo de resistência e unidade nacional, além de um aliado fiel que garantiria a continuidade da Grécia como tradicional subordinada de Londres ${ }^{8}$ e parte constituinte da linha vital do Império Britânico9 (FRAZIER, 1991). Pari passu, a EAM-

\footnotetext{
8 Desde a guerra de independência grega contra o Império Otomano (1821-1832), os ingleses mantinham uma relação de hegemonia sobre a nação helênica, e foram os principais agentes de pressão externa na Grécia até 1947, quando do advento da Doutrina Truman, que pavimentou as condições para que os EUA se tornassem preponderantes (SAKKAS, 2007). Antes dessa data, os sucessivos governos britânicos agiram na Grécia desprezando as formalidades constitucionais, pressionando pela dispensa e nomeação de primeiros ministros, e especialistas britânicos "[...] ditavam a política econômica, a política externa e de defesa, a política legislativa, a política de segurança e as políticas sindicais” (WOODHOUSE apud SAKKAS, 2007, p. 17).

9 A Grécia era importante para os britânicos por fazer parte de uma rede de pontos estratégicos no Mediterrâneo, junto de Gibraltar, Malta e Chipre, sobre os quais Londres exercia hegemonia (quando não presença militar direta). Esses pontos, somados ao Canal de Suez no Egito, formavam a linha vital de comunicações do Império Britânico, essencial para a circulação de mercadorias e para o deslocamento da Marinha Real entre as ilhas britânicas e as colônias no subcontinente indiano. Ademais, era considerável a presença econômica inglesa, na forma de empréstimos ao governo e controle e/ou propriedade de importantes empresas que atuavam na Grécia. Ainda que a nação helênica jamais tenha integrado o Império Britânico oficial, podemos dizer que ela fez parte daquilo que Porter (1996) chamou de império informal: regiões do globo que não faziam parte do sistema de colônias, protetorados, domínios e mandatos, mas nas quais
} 
ELAS e outros grupos guerrilheiros menores foram abastecidos com dinheiro, armamentos e equipamentos por outra agência governamental britânica, a Special Operations Executive (SOE), que tinha o intuito de causar o máximo possível de dano aos nazistas. Esse auxílio facilitou o fortalecimento e expansão do ELAS, que durante a guerra conquistou o controle de quase todo o território grego (HOROWITZ, 1965), com influência particularmente forte nas regiões montanhosas, onde seus empreendimentos sociais foram notáveis, podendo ser considerados como a constituição de um Estado organizado em áreas até então negligenciadas, conseguindo de fato elevar as condições de vida da população (WOODHOUSE apud LOWE, 2017).

Ao fim da ocupação, em outubro de 1944, tropas britânicas aportaram na Grécia enquanto o Foreign Office fazia preparativos para restaurar a monarquia. Advinda de um golpe de estado que em 1935 extinguiu a Segunda República Helênica, a monarquia não tardou a se metamorfosear de um regime parlamentar em uma ditadura: no dia 4 de agosto de 1936, sob o pretexto de impedir o avanço do KKE na política institucional, o primeiro ministro Ioannis Metaxas decretou estado de emergência e dissolveu o parlamento com o apoio de George II. O Regime de Quatro de Agosto (como ficou conhecido o período de Metaxas) foi notório pela perseguição aos comunistas e outros políticos de esquerda, e também pela repressão de greves e manifestações (PAPANDREOU, 1973). Dado esse histórico, não surpreende que os líderes da EAM avaliassem a situação com desconfiança. Não obstante, a organização, com mediação britânica, chegou a um acordo com o governo provisório, concordando em reconhecer e compor o novo Governo de Unidade Nacional, no qual George II seguiria como monarca e o socialista Georgios Papandreou atuaria como primeiro ministro, em um regime parlamentar.

O acordo foi fragilizado, todavia, quando o novo governo trouxe do exílio duas unidades militares realistas compostas majoritariamente por contingentes de direita - a Brigada das Montanhas e o Esquadrão Sagrado. Isso levou à avaliação, por parte das lideranças da EAM, de que os grupos de resistência precisariam manter seus armamentos, na tentativa de se estabelecer uma relação de forças equilibrada. Na noite do dia primeiro de dezembro de 1944, seis ministros da EAM (dois deles pertencentes ao KKE) se recusaram a assinar um decreto de desmobilização incondicional de todas as organizações guerrilheiras entre os dias 16 e 20 de dezembro, e renunciaram aos seus assentos em protesto. O comitê central da EAM convocou seus membros e apoiadores para uma manifestação contra a exigência de desarmamento, no dia 3 de dezembro, na Praça Syntagma em frente ao Parlamento Helênico, no centro de Atenas.

Milhares compareceram. A escalada nas tensões não demorou a levar a um choque entre a polícia e os manifestantes. Embora até hoje não haja consenso a respeito do número de mor$\operatorname{tos}^{10}$ (GEROLYMATOS, 2016), o fato é que os policiais posicionados em frente ao Parlamento dispararam contra a multidão, resultando em mortos e feridos. Esse evento desencadeou uma batalha brutal entre a EAM-ELAS e o Governo de Unidade Nacional, que veio a ser conhecida

os britânicos exerciam uma hegemonia decorrente principalmente de sua expansão econômica que se tornou mais evidente a partir de meados do século XIX.

1o Gerolymatos (2016) menciona que as mais variadas fontes e estudos trazem estimativas muito díspares, variando entre menos de duas dezenas e quase duas centenas de mortos. 
como Dekemvriana - "os eventos de dezembro" em grego. O conflito se arrefeceu provisoriamente apenas em 12 de fevereiro de 1945 com o Acordo de Varkiza, no qual o ELAS depôs suas armas. Os soldados britânicos estacionados em Atenas, que nos primeiros momentos procuravam uma intervenção mínima, se viram cada vez mais envolvidos nos combates, e passaram a entrar em confronto direto com os guerrilheiros do ELAS (GEROLYMATOS, 2016).

\section{2 "Nós, pessoas trabalhadoras, estamos furiosas com o que está acontecendo na Grécia"}

Enquanto o caos engolfava Atenas, o Parlamento Britânico se tornou palco de acirrados debates acerca da intervenção britânica na Grécia, tanto na Câmara dos Lordes quanto na Câmara dos Comuns. Um exame das transcrições dos debates ${ }^{11}$ mostra que vários pontos foram levantados acerca dessa questão: a pertinência ou não de utilizar na Grécia recursos humanos e militares que poderiam ser empregados no combate à Alemanha; um possível amotinamento dos soldados que lutavam contra o ELAS; as consequências políticas e estratégicas de se envolver em uma guerra civil etc. Em sua intervenção, Frederick Pethick-Lawrence (membro do Partido Trabalhista e representante do distrito ${ }^{12}$ de Edinburgh East) na Câmara dos Comuns, no dia 5 de dezembro de 1944, refere-se à "[...] grave ansiedade sentida em todas as seções deste país [o Reino Unido] em relação ao que tem se passado [na Grécia]” (HOUSE OF COMMONS, 1944, p. 359). Depois de algumas trocas entre Pethick-Lawrence e Churchill - nas quais o primeiro-ministro menciona que os acontecimentos na Grécia vinham recebendo cobertura contínua da imprensa britânica - , Leslie Haden-Guest, outro membro do Partido Trabalhista, representante de Islington North, propõe (sem sucesso) que o encerramento da sessão do dia seja adiado, para que os parlamentares possam “[...] discutir a situação grave que surgiu na Grécia como resultado dos tiros disparados pela polícia contra uma manifestação no domingo, três de dezembro, como um assunto de importância pública urgente" (HOUSE OF COMMONS, 1944, p. 361).

Os detalhes que destacamos dessa discussão são significativos: apenas dois dias após o início dos conflitos, as ações britânicas na Grécia foram consideradas um assunto urgente, de interesse público, gerador de apreensão popular, e também se constatou que a imprensa, de modo geral, estava amplamente interessada no assunto. Mais de um mês depois, no dia 19 de janeiro de 1945 - enquanto a Grécia ainda estava mergulhada na violência -, Percy Harris, representante pelo Partido Liberal de Bethnal Green South West, declarou, no início de sua intervenção:

O país [Reino Unido] está indubitável e profundamente comovido. É um erro crasso pensar que [essa comoção] [...] é uma agitação organizada engendrada por algum grupo político. Sem dúvida houve políticos preparados para lucrar nas

\footnotetext{
${ }^{11}$ Utilizamos as transcrições disponibilizadas online no site Hansard: https://api.parliament.uk/historic-hansard/index.html. Acesso em 12 out. 2019 .

12 Os britânicos utilizam o termo constituency, sem tradução exata para o português nesse sentido, por isso optamos por traduzir como distrito. No Reino Unido, cada uma das constituencies elege um membro para a Câmara os Comuns, como no caso que ora examinamos, e também para outros parlamentos ou assembleias.
} 
emoções do público, mas eu encontro tanto na direita quanto na esquerda um sentimento de tristeza e tragédia quanto ao fato de que, antes que a [segunda] guerra [mundial] tenha terminado, nós vemos guerra civil e nossas tropas nela engajadas tentando restaurar a ordem (HOUSE OF COMMONS, 1945, p. 515).

Podemos inferir, a partir das falas dos parlamentares, que havia amplo interesse público pela questão grega - dada a constatação de que esse era um tema sempre presente na imprensa —, e havia considerável desconforto em parte da população em relação à linha de intervenção na Grécia defendida por Churchill. O exame das transcrições dos debates no Parlamento nos levou a buscar evidências da percepção das pessoas comuns acerca das incursões britânicas na Grécia, o que se mostrou um empreendimento árduo. Se os estudos históricos são sempre, em maior ou menor medida, lacunares e provisórios, a perspectiva que buscamos aqui apresenta uma dificuldade adicional levantada por Lüdtke (1995): os registros deixados pelas chamadas pessoas comuns que podem ser utilizados como fonte de pesquisa são escassos e devem ser tratados com cautela. A maneira que encontramos de contornar essa dificuldade foi buscar os periódicos da época - mais especificamente, nas páginas do diário Daily Worker.

A escolha pelo jornal em questão não é fortuita. Cruz e Peixoto (2007) lembram que todas as fontes de pesquisa histórica possuem uma dimensão subjetiva, posto que elas mesmo são produtos históricos - e por isso é necessário localizar o lugar de onde falam os autores dos documentos, seus interesses, estratégias, intenções e técnicas. Quando utilizamos jornais como fonte de pesquisa, não podemos tomá-los como "[...] objetos mortos, descolados das tramas históricas nas quais se constituem" (CRUZ; PEIXOTO, 2007, p. 256). A imprensa é uma força ativa na vida moderna, atuando na constituição dos nossos modos de vida, perspectivas e consciência histórica, muito além de ser mero depositário de acontecimentos. Os jornais devem ser considerados em suas articulações com os campos de luta mais amplos nos quais as publicações se constituem e atuam (CRUZ; PEIXOTO, 2007).

Com base nessas reflexões, avaliamos o Daily Worker como a fonte disponível mais profícua para nossos objetivos - examinar as manifestações de pessoas comuns contrárias à política britânica na Grécia. Trata-se de um jornal fundado em 1930 pelo comitê central do Partido Comunista da Grã-Bretanha (GBCP) com o intuito de noticiar e analisar questões relacionadas à política, aos movimentos e demais questões das classes trabalhadoras britânicas. O público alvo eram essas mesmas classes trabalhadoras - e não apenas membros do Partido, como pode atestar uma breve comparação numérica. Os filiados ao GBPC atingiram seu número máximo justamente nos últimos momentos da Segunda Guerra Mundial: cerca de 60 mil membros (WHEELER, 2012). Não há consenso quanto às tiragens do Daily Worker para a mesma época, mas as estimativas variam entre um mínimo de 100 mil exemplares (HAYLET, 2005) e um máximo de 500 mil cópias diárias - lembrando que a Grã-Bretanha possuía então cerca de 48 milhões de habitantes (PLATT, 2015). Sua proposta editorial se alinhava à estratégia do Partido de alcançar o socialismo nas ilhas britânicas por intermédio da liderança dos trabalhadores e suas organizações (sindicatos, conselhos etc.) que exerceriam democraticamente a luta contra os monopólios capitalistas. É razoável supor, portanto, que 
a maioria (ou, ao menos, parte considerável) de seus leitores fosse favorável às causas e aos movimentos de esquerda britânicos e da Europa Continental.

O jornal apoiava o esforço de guerra do governo desde junho de 1941, quando a Alemanha deu início à Operação Barbarossa contra a União Soviética, e participou das campanhas pela abertura da segunda frente na guerra em 1942. Contudo, quando as forças armadas britânicas entraram em choque com os guerrilheiros comunistas gregos, o Daily Worker se posicionou veementemente contrário a essas ações. Como se tratava de um periódico bem variado e elaborado - oito páginas em formato tabloide, trazendo editoriais, reportagens, colunas, cartas de leitores etc. - , veiculou diversas expressões de oposição, principalmente por intermédio da cobertura e menção de manifestações públicas e da publicação de mensagens de seus leitores.

A abordagem desse tema no jornal se tornou mais frequente após o dia cinco de dezembro de 1944. Nessa data, em sessão da Câmara dos Comuns, Churchill defendeu ampla e ferrenhamente a atuação das tropas britânicas como a ação necessária para assegurar que o povo grego tivesse a oportunidade de escolher democraticamente seu governo, uma vez que o ELAS - segundo ele - pretendia estabelecer pela força uma ditadura comunista. Sua intervenção foi amplamente divulgada na imprensa (não raro com transcrições dos trechos mais impactantes de seu discurso), o que gerou reações negativas em consideráveis setores da sociedade britânica, parte das quais foram registradas pelo Daily Worker. A edição de 11 de dezembro de 1944 informou que no final de semana anterior (dias 9 e 11) ocorreram algumas manifestações de tamanho variável em protesto contra a linha de ação empreendida por Churchill na Grécia: cerca de 2300 pessoas no Albert Hall de Nottingham no sábado; duas mil pessoas no Chelsea e aproximadamente 600 pessoas no teatro Hackney Empire, em Londres. O Trades Council de Londres exigiu uma resolução de emergência clamando pelo fim da intervenção, enquanto os trabalhadores dos estaleiros da conurbação de Tyneside, no nordeste da Inglaterra, realizaram duas conferências durante o final de semana, depois das quais emitiram uma resolução protestando contra o fato de que os navios por eles construídos transportavam tropas e armamentos que seriam usados contra o povo grego. A mesma edição trouxe ainda uma lista de outras organizações sindicais que manifestaram protestos oficiais ${ }^{13}$.

A edição de 13 de dezembro de 1944 informa que foi enviado um telegrama ao governo contendo um protesto conjunto em nome tanto da gerência quanto dos trabalhadores da Standard Motor Company, fábrica automobilística instalada em Coventry, que participou do esforço de guerra produzindo aeronaves de combate, veículos militares, e motores e fuselagem para aviões. "Enquanto continuamos a cooperar na produção de armas para a derrota da Alemanha Nazista, deploramos seu uso contra o povo grego", registrava o telegrama, que também fazia menção à Carta do Atlântico e sua determinação de que os povos libertados do nazismo deveriam ter o direito de escolher seus próprios governos ${ }^{14}$. O conselho executivo da Sociedade dos Trabalhadores em Construção e Construtores Nacionais também emitiu uma resolução solicitando que o governo

13 DAILY WORKER, Nova York, p. 4, 11 dez. 1944.

14 apud DAILY WORKER, Nova York, p. 3, 13 dez. 1944. 
britânico se dissociasse das ações do governo grego de Papandreou, e que deixasse de interferir nos assuntos internos dos povos libertados do nazismo. A Federação Liberal de Mulheres, organização ligada ao Partido Liberal, tradicional opositor do Partido Conservador, também tornou públicas suas críticas em uma resolução, “[...] deplorando amargamente a política que levou ao derramamento de sangue entre as nossas tropas e o ELAS, e exigindo que o governo tome todos os passos necessários na busca de um armistício com o objetivo de se chegar a um acordo" .

Alguns dias depois, a primeira página da edição de 16 de dezembro de 1944 do mesmo jornal traz uma chamada para uma manifestação organizada pela secretaria geral do Sindicato das Brigadas de Bombeiros, a se realizar no dia seguinte, na Trafalgar Square de Londres, para que "o povo londrino" demonstre "sua profunda preocupação quanto à política do governo na Grécia”" Na edição de 18 de dezembro, o correspondente Frank Pitcairn afirmou que todo o espaço da Trafalgar Square foi ocupado por manifestantes - o maior ato público ocorrido em Londres desde a época em que o povo saiu às ruas exigindo a abertura da segunda frente na guerra. O texto da resolução que circulou entre a multidão declarou:

Esta reunião de cidadãos londrinos condena a política desastrosa do governo britânico em relação à Grécia. Essa política está sacrificando vidas britânicas em ações não contra os fascistas, mas contra aqueles que têm sido os mais firmes combatentes contra o fascismo. Esta política deve ser revertida. [...] Nós juramos ao povo da Grécia que trabalharemos incessantemente para que isso [a reversão da política] seja alcançado ${ }^{16}$.

A mesma edição do periódico reporta que trabalhadores das cidades de Glasgow e Dumbarton (ambas na Escócia) também realizavam várias reuniões e manifestações em suas cidades para protestar contra as políticas do governo. Em Coventry, cidade inglesa de West Midlands, o prefeito, George Hodgkinson, afirmou estar planejando um ato público de protesto, esperando contar com o auxílio dos moradores da cidade na organização. Ao jornal, Hodgkinson declarou: "Eu aqui registro, como prefeito, o profundo sentimento de repulsa que existe entre os cidadãos da área quanto à situação na Grécia” (apud THE DAILY WORKER, Nova York, p. 3, 18 dez. 1944). Além disso, também foram registrados protestos na área metropolitana de Manchester e em várias regiões do País de Gales.

O grande número de organizações que protestaram de uma forma ou de outra, bem como a adesão a essas manifestações, são indícios de que a atuação das tropas britânicas na Grécia era questionada de maneira considerável. Nossas fontes também trazem indícios de manifestações individuais de descontentamento. A seção de correspondência dos leitores de cinco de dezembro de 1944 traz uma carta de um residente de Chichester, D. M. Collar. Esse leitor condena de maneira geral a forma como as forças britânicas agiam em vários países recém-libertados:

15 DAILY WORKER, Nova York, p. 1, 16 dez. 1944.

16 apud THE DAILY WORKER, Nova York, p. 1, 18 dez. 1944. 
O mundo aprendeu, com horror, que as tropas britânicas têm sido usadas para manter "a lei e a ordem" na Bélgica - em outras palavras, para apoiar um governo reacionário contra os desejos do povo. A situação na Grécia e na Itália também dá base para consternação. Não seria agora o momento para o movimento Trabalhista protestar de todas as formas possíveis contra esse uso de poder militar que faz chacota da palavra "liberação"? ${ }^{17}$.

No dia seguinte, novamente a Grécia foi comparada à Bélgica, desta vez por J. Shanley, para quem os eventos nesses dois países mostravam que com a perspectiva de uma vitória sobre o nazismo no campo militar, “[...] as forças da reação estão se aglutinando, determinadas a parar qualquer tentativa por parte dos trabalhadores de fazer mudanças democráticas fundamentais" ${ }^{18}$. Cinco dias depois, temos a mensagem de uma residente de Londres, Eva Melnick. Ela dizia ter um amigo que fez parte das forças britânicas que aportaram na Grécia quando da libertação dos nazistas, tendo sido recebidas por "[...] braços abertos, saudações e flores". ${ }^{19}$ Essa recepção calorosa torna ainda mais odioso o fato de que

[...] agora, esse povo [grego] [...] esteja sendo submetido a horrores que se esperaria [apenas] da ocupação nazista. Movimentos da esquerda são perseguidos e movimentos da direita são encorajados e permitidos a seguir em frente com todas as possibilidades de se estabelecer uma ditadura. Teremos perdido de vista pelo que estamos lutando? E quanto aos outros países que ainda estão por serem libertados? O senhor Churchill disse que qualquer homem que lute contra os nazistas teria a nossa ajuda. Terá ele se esquecido disso em tão pouco tempo $?^{20}$

A mesma edição traz também uma mensagem assinada por Tobruk defender (defensor de Tobruk), um antigo membro das Forças Expedicionárias Britânicas que lutaram na Primeira Guerra Mundial. O ex-soldado se diz “enojado” pelos assassinatos de aliados gregos cometidos por britânicos, e alerta: "nossos garotos que estão lá não vão gostar do trabalho que estão sendo obrigados a fazer na Grécia”. ${ }^{21}$ Outro leitor, A. T. D’Eye, de Canterbury, também expressou sua indignação:

Que direito nós temos de determinar que tipo de governo a Grécia deve ter? Por quanto tempo a Grécia tem sido uma colônia britânica? É esse o significado das Quatro Liberdades, ou da Carta do Atlântico? Que escárnio! Nossos mortos devem se levantar de seus túmulos perante essa traição de tudo pelo que eles lutaram e sofreram. ${ }^{22}$

Exatamente uma semana depois, uma moradora de Acton chamada Kaye Ford protestou:

DAILY WORKER, Nova York, p. 2, 5 dez. 1944.

18 DAILY WORKER, Nova York, p. 2, 6 dez. 1944.

19 DAILY WORKER, Nova York, p. 2, 11 dez. 1944

20 DAILY WORKER, Nova York, p. 2, 11 dez. 1944

${ }^{21}$ DAILY WORKER, Nova York, p. 2, 11 dez. 1944

22 DAILY WORKER, Nova York, p. 2, 11 dez. 1944 
Eu tenho um marido, irmãos, e mais de 50 parentes nas forças armadas. Nós, pessoas trabalhadoras, estamos furiosas com o que está acontecendo na Grécia. Esses homens [os soldados britânicos na Grécia] foram recebidos de braços abertos pelas mesmas pessoas que eles receberam ordens de matar. Nós estamos orgulhosas de ter nossos homens lutando contra a escória imunda fascista. [Mas] Hoje nós estamos furiosos e envergonhados em saber que eles estão matando um povo que sofreu e lutou ao nosso lado por tanto tempo. ${ }^{23}$

Os registros aqui mostrados nos permitem vislumbrar um elemento comum em uma quantidade considerável de manifestações de oposição, sejam elas individuais (na forma de cartas ao jornal) ou coletivas (manifestações em locais públicos e pronunciamentos oficiais de algumas organizações). Comecemos pelo protesto conjunto da Standard Motor Company. Seus trabalhadores e gerentes deixaram explícito que apoiavam a luta contra o nazismo tanto que declaram que continuariam a fabricar armamentos e contribuir para a derrota da Alemanha -, e colocaram essa luta, considerada justa, em franca oposição ao que as tropas britânicas estavam empreendendo na Grécia.

Também é significativa a menção à Carta Atlântica, assinada em 14 de agosto de 1941 por Churchill e o presidente estadunidense Franklin Roosevelt a bordo do couraçado britânico HMS Prince of Wales nos arredores da província canadense de Terra Nova e Labrador. Por intermédio desse documento, Roosevelt e Churchill pretendiam tornar conhecidos “[...] certos princípios comuns nas políticas nacionais de seus respectivos países, nos quais eles baseiam suas esperanças em um futuro melhor para o mundo" (ATLANTIC CHARTER, 1941, n.p.). O terceiro ponto da carta prega o direito de todos os povos de escolher o governo sob o qual desejam viver, e garante o desejo britânico e estadunidense de "[...] ver restaurados os direitos soberanos de autodeterminação para aqueles que tiveram esses direitos retirados a força" (ATLANTIC CHARTER, 1941, n.p.). O sexto ponto expressa a expectativa de que, "depois da destruição final da tirania nazista”, estabeleça-se uma paz que possibilite que "[...] todos os homens vivam suas vidas livres do medo e da carência" (ATLANTIC CHARTER, 1941, n.p.).

A manifestação da Standard Motor Company deixa claro que, na visão de seus signatários, o governo britânico teria abandonado os valores expressos na Carta. A política externa na Grécia iria de encontro aos princípios de liberdade e direito à autodeterminação. Em uma perspectiva mais ampla, a Grã-Bretanha teria entrado em contradição com os valores que impulsionaram a luta contra o nazismo. Em sua carta ao Daily Worker, o leitor A. T. D’Eye também faz referência à discrepância entre a questão grega e a observância dos princípios expressos na Carta do Atlântico, e cita as “Quatro Liberdades”, que também estariam sendo pervertidas. Podemos inferir que D'Eye se referiu ao discurso, com o qual certas passagens da Carta do Atlântico se assemelham, proferido por Roosevelt perante o Congresso estadunidense no dia seis de janeiro de 1941, com o intuito de quebrar a política de neutralidade então mantida pelos EUA: todos os

DAILY WORKER, Nova York, 18 dez. 1944. 
homens deveriam ter asseguradas as liberdades de expressão, de adorar a Deus segundo seus próprios modos, bem como assegurar a liberdade em relação ao medo e à carência.

Em comum com os protestos citados, o texto da resolução da manifestação de 16 de dezembro da Trafalgar Square traz a questão do fascismo vinculada ao que se desenrolava na Grécia: os esforços e recursos britânicos deveriam ser concentrados em derrotar o fascismo, não em combater aqueles que até recentemente eram aliados dos britânicos contra o fascismo. Em suas cartas, D. M. Collar e J. Shanley opinaram que a conduta de seu governo fazia na nação helena dava vantagens apenas às forças reacionárias locais, o que, segundo Collar, esvazia todo o sentido da palavra "liberação". Eva Melnick considera as ações de seu governo na Grécia semelhantes às atrocidades cometidas pelos nazistas. Isso seria uma prova clara de que a Grã-Bretanha teria perdido os princípios pelos quais combatia o nazismo e toda a opressão por ele representada. Kaye Ford, por sua vez, aclara a dicotomia: combater o fascismo é motivo de orgulho; combater guerrilheiros gregos é motivo de fúria e vergonha.

\section{Considerações finais}

É razoável considerar, portanto, que os protestos aqui analisados se baseiam primordialmente em uma questão de valores - e não em elementos mais pragmáticos, referentes, por exemplo, a gastos econômicos ou a estratégias militares. A intervenção britânica na Grécia era considerada não apenas injusta, mas um abandono completo dos valores nos quais se baseariam a política da Grã-Bretanha - a liberdade, a democracia e a defesa do direito à autodeterminação e condições de vida digna para todos os povos do planeta. Tais valores foram amplamente difundidos entre os britânicos, em parte por conta do esforço de guerra, como um movimento de demarcação da oposição entre os britânicos e seus aliados e o autoritarismo nazifascista. Os guerrilheiros do ELAS, por sua vez, até poucos dias antes do início do conflito em Atenas eram vistos como aliados dos britânicos contra o fascismo - esse vínculo fica claro nas cartas examinadas.

Durante os eventos de dezembro de 1944, as tropas britânicas não apenas entraram em conflito com um grupo que até pouco tempo atrás era considerado aliado, como passaram a defender um governo cujo passado, como vimos, era intimamente ligado à ditadura de Metaxas - que, por sua vez, apresentava semelhanças consideráveis aos regimes de Mussolini e Hitler. Logo, essas ações seriam uma traição aos valores basilares da sociedade britânica, aproximando-a assim, do nazifascismo que havia sido combatido a duras penas. É significativa a expressão de A. T. D'Eye em sua carta: nossos mortos, que sofreram e lutaram por um mundo mais livre e justo, deveriam estar perturbados em seus túmulos, perante tamanha traição dos princípios pelos quais tantas pessoas se sacrificaram. Tratava-se, pois, de uma percepção que colocava a Grã-Bretanha como portadora do dever se assegurar a liberdade e a autodeterminação dos povos ao redor do mundo - ideia fortalecida principalmente pela luta contra o fascismo. Assim, a incursão na Grécia teria pervertido a sociedade britânica, desviando-a de sua verdadeira essência.

Certamente, não podemos deixar que as fontes escolhidas nos levem a superestimar a abrangência da crítica às ações na Grécia. Cruz e Peixoto (2007) lembram que o passado não nos lega 
testemunhos neutros e objetivos, e que todo documento é o suporte de uma prática social, articulado pela intencionalidade histórica que o constitui. Os membros do Daily Worker eram claramente contrários à incursão britânica na Grécia, e utilizavam o periódico para divulgar e incentivar²4 as manifestações contrárias ao governo, tendo, portanto, interesse político em salientá-las ${ }^{25}$.

Todavia, como mostramos, o desconforto público em torno desta questão foi considerado forte o bastante para ser motivo de preocupação nos debates da Câmara dos Comuns. Ademais, e o número considerável de organizações que de alguma forma expressaram seu protesto nos leva a crer que não se tratava de algo desprezível ${ }^{26}$. Ao menos em parte dos cidadãos britânicos que expressavam sua contrariedade à intervenção na Grécia, havia o sentimento de que sua pátria traía, na Grécia, os ideais de liberdade, democracia e autodeterminação sobre os quais ela seria fundada.

\section{Referências}

ARRIGHI, Giovanni. The long twentieth century: Money, Power and the origins of our times. London: Verso, 2010.

ATLANTIC CHARTER. 1941. Disponível em: http://web.ics.purdue.edu/ wggray/Teaching/ His300/Handouts/Atlantic-Charter.pdf. Acesso em: 19 mar. 2019.

BARRACLOUGH, Geoffrey. Introdução à história contemporânea. Rio de Janeiro: Zahar, 1966.

BERGERSON, Andrew Stuart. Ordinary Germans in extraordinary times: the Nazi revolution in Hildesheim. Bloomington: Indiana University Press, 2004. https://doi.org/10.1086/509195

CORDEIRO, Janaína Martins; MAGALHÃES, Livia Gonçalves. Por uma história do cotidiano nos regimes autoritários do século XX. Estudos Íbero-Americanos, Porto Alegre, v. 43, n. 2, p. 242-249, maio-ago. 2017. https://doi.org/10.15448/1980-864X.2017.2.27337

CRUZ, Heloísa de Farias; PEIXOTO, Maria do Rosário da Cunha. Na oficina do historiador: conversas sobre história e imprensa. Projeto História, São Paulo, n. 35, p. 253-270, dez. 2007.

DAILY EXPRESS. Londres, 18 dez. 1944.

\footnotetext{
24 Nas edições que analisamos há várias chamadas anunciando os locais e horários das próximas manifestações públicas contra a intervenção britânica.

${ }_{25}$ Um texto de opinião - não assinado e cuja autoria não fomos capazes de decifrar - publicado no jornal Daily Express no dia 18 de dezembro de 1944, por exemplo, interpreta a manifestação do dia 17 de dezembro de forma diversa da avaliação do Daily Worker. "Quantas pessoas compareceram ontem à manifestação na Trafalgar Square para protestar contra a política do governo britânico na Grécia? A estimativa da polícia é de cerca de cinco mil pessoas. Quantas pessoas compareceram à manifestação pedindo pela abertura da segunda frente em 1942 ? Entre trinta e quarenta mil. Em Manchester, apenas duas mil pessoas se manifestaram [contra as ações britânicas na Grécia], em comparação com as cerca de seis mil na questão da segunda frente. [...] [O número reduzido de manifestantes ontem, em comparação às manifestações pela segunda frente][...] não significa que o povo de Londres e Manchester não tenha simpatia pelo povo grego. Mas significa que ainda há fé nas intenções do governo britânico em relação aos gregos. Isso significa também que as tentativas das minorias da esquerda em transformar essa questão em uma grande crise falharam. Todos querem trazer um fim para a trágica luta na Grécia o mais rapidamente possível. Seria tolice acreditar que o governo britânico tem qualquer outro desejo." (DAILY EXPRESS, 18 dez. 1944, p.2).

${ }_{26}$ O resgate feito por Sakkas (2007) dos resultados de uma pesquisa de opinião conduzida pelo British Gallup Institute e publicada em janeiro de 1945 (o mês seguinte ao tratado aqui) nos permite inferências no mesmo sentido: "Em janeiro de 1945, quando a crise grega estava no ápice, $43 \%$ do povo britânico aprovava a atitude de Churchill quanto à questão grega, $38 \%$ desaprovava enquanto $19 \%$ não expressaram opinião. Os números sugerem que, em um período em que Churchill, como resultado de seu esforço de guerra, dispunha do apoio massivo do povo britânico, sua política na Grécia e sua atitude geral em relação a movimentos de resistência eram questionadas [por expressiva parcela da população]" (SAKKAS, 2007, p.51).
} 
DAILY WORKER. Nova York, 5 dez. 1944.

DAILY WORKER. Nova York, 6 dez. 1944.

DAILY WORKER. Nova York, 11 dez. 1944.

DAILY WORKER. Nova York, 13 dez. 1944.

DAILY WORKER. Nova York, 16 dez. 1944.

DAILY WORKER. Nova York, 18 dez. 1944.

FRAZIER, Robert. Anglo-american relations with Greece: the coming of the Cold War, 1942-1947. New York: St Martin's Press, 1991. https://doi.org/10.1086/ahr/98.2.475

GEROLYMATOS, André. An international civil war: Greece, 1943-1949. New Haven: Yale University Press, 2016.

HAYLLET, Jonh. Still flying the red flag. Independent, Londres, May 23, 2005. Disponível em: https://www.independent.co.uk/news/media/still-flying-the-red-flag-491723.html. Acesso em: 19 mar. 2019.

HOROWITZ, David. The free world colossus: a critique of american foreign policy in the Cold War. New York: New and Wang, 1965.

HOUSE OF COMMONS. Greece (Disturbances, Athens). ). HC Deb o5 Dec. 1944, v. 406. Disponível em: https://api.parliament.uk/historic-hansard/commons/1944/dec/o5/greece-disturbances-athens. Acesso em: 25 jan. 2019.

HOUSE OF COMMONS. Liberated Europe (British intervention). HC Deb o8 Dec. 1944, v. 406. Disponível em: https://api.parliament.uk/historichansard/ commons/1944/dec/o8/liberated-europe-british-intervention. Acesso em: 25 jan. 2019.

HOUSE OF COMMONS. War situation and foreign policy. HC Deb 19 Jan. 1945, v. 407. Disponível em: https://api.parliament.uk/historic-hansard/commons/1945/jan/18/war-situation-and-foreign-policy. Acesso em: 25 jan. 2019.

IATRIDES, John. Revolt in Athens. Princenton: Princenton University Press, 1972.

KOUSOULAS, G. Revolution and defeat: the story of the greek communist party. Oxford: Oxford University Press, 1965.

LOWE, Keith. Continente selvagem: o caos na Europa após a Segunda Guerra Mundial. Rio de Janeiro: Zahar, 2017.

LÜDTKE, Alf. What is the History of Everyday Life and who are its practioners? In: LÜDTKE, Alf. (org.). The History of Everyday Life. Princeton: Priceton University Press, 1995, p. 3-40. https://doi.org/10.1515/9781400821648-002

O’BALANCE, Edgar. The greek civil war. New York: Praeger, 1966.

PAPANDREOU, Andreas. Democracy at gunpoint: the Greek front. Middlesex: Pelican Books, 1973.

PLATT, Edward. Inside the Morning Star, Britain's last communist newspaper. New Statesman, Nova York, Aug 4, 2015. Disponível em: https://www.newstatesman.com/2015/o7/red-all-over-article. Acesso em: 19 mar. 2019.

PORTER, Bernard. The Lion's share: a short history of british imperialism 1850-1995. London: Longman, 1996. 
SAKKAS, John. Old Interpretations and New Approaches in the Historiography of the Greek Civil War. Thetis 20, [s. n.], p. 1-20, 2013. Disponível em: www.academia.edu/john-sakkas-oldinterpretations-new-approaches-greek-civil-war. Acesso em: 01 jun. 2019.

SAKKAS, Jonh. Britain and the Greek Civil War, 1944-1949: British imperialism, public opinion and the coming of the Cold War. Berlim: Verlag, 2007.

TSOUKALAS, Constantine. The greek tragedy. London: Penguin, 1969.

WHELLER, Brian. What happened to the Communist Party of Great Britain's millions? BBC News, Londres, Jun 13, 2012. Disponível em: https://www.bbc.com/news/uk-politics-18351323. Acesso em: 19 mar. 2019.

WOODHOUSE, C. M. The struggle for Greece. New York: Ivan Dee, 2002.

Enviado em: 25/6/2019.

Aprovado em: 22/8/2019.

Felipe Alexandre Silva de Souza

\section{Endereço postal:}

Rua Prof. Marcos Valdemar de Freitas Reis, s/n, Bloco O

Campus do Gragoatá, Bairro: São Domingos - Niterói/RJ - Brasil

CEP: $24210-200$ 